\title{
Thin GaAsSb capping layers for improved performance of InAs/GaAs quantum dot solar cells
}

\author{
A.D. Utrilla , D.F. Reyes , J.M. Llorens , I. Artacho , T. Ben , D. González , ž. Gačević , \\ A. Kurtz , A. Guzman , A. Hierro , J.M. Ulloa
}

\begin{abstract}
A B S T R A C T
This work reports on the benefits from using thin GaAsSb capping layers (CLs) on InAs/GaAs quantum dot (QD) solar cells. The application of such CLs allows the tunability of the QD ground state, switching the QD-CL band alignment from type I to type II for high Sb contents and extending the photoresponse beyond $1.5 \mu \mathrm{m}$. Two different structures with $\sim 10 \%$ and $\sim 20 \% \mathrm{Sb}$ contents in the CL (type-I and type-II band alignments, respectively) are explored, leading to efficiency improvements over a reference InAs/ GaAs QD solar cell of $20 \%$ and $10 \%$, respectively. In general, a significant increase in short-circuit current density $\left(\mathrm{J}_{\mathrm{sc}}\right)$ is observed, partially due to the extended photocurrent spectrum and the additional contribution of the CL itself. Particularly, for a moderate Sb content, an improved carrier collection efficiency is also found to be a main reason for the $\mathrm{J}_{\mathrm{sc}}$ increase. Calculations from an $8 \times 8 \mathrm{k} \cdot \mathrm{p}$ method suggest the attribution of such an improvement to longer carrier lifetimes in the wetting layer-CL structure due to the transition to a type-II band alignment. Open-circuit voltages $\left(V_{o c}\right)$ exceeding that of a reference QD solar cell are demonstrated under light concentration using GaAsSb CLs, which proves that the $V_{o c}$ is not limited by the low bandgap CLs. Moreover, the highest value is obtained for the high Sb content type-II structure, despite the higher accumulation of strain and the lower effective bandgap. Indeed, the faster $V_{o c}$ increase with light power found in the latter case leads to an $V_{o c}$ even larger than the effective bandgap.
\end{abstract}

\section{Introduction}

The benefits from using GaAsSb capping layers (CLs) on InAs quantum dots (QDs) are already well known. The application of such CLs was first proposed as a means to control the emission wavelength from the InAs QD ground state [1], and allowed the achievement of the long-wavelength window for optical communications [2,3]. Although the overall strain in the structure is increased, GaAsSb CLs over InAs QDs act as strain-reducing layers leading to the suppression of the QD decomposition [4] by the inhibition of the strain-driven In-Ga intermixing during the capping process. The preservation of the $\mathrm{QD}$ height is believed to enhance the carrier confinement so that improved room-temperature photoluminescence is obtained for moderate amounts of $\mathrm{Sb}$ [5]. On the other hand, for an Sb content around 16-17\%, the
QD-CL band structure switches from a type-I to a type-II band alignment, with the holes localized outside the $\mathrm{QD}$ in the $\mathrm{CL}$. This reduces the oscillator strength and, therefore, increases the radiative carrier lifetime [6-8]. Nevertheless, these type-II structures can show improved luminescence and a highly tunable excitonic geometry and topology $[9,10]$.

As a result of all this, GaAsSb CLs have been shown to provide improved performance in different optoelectronic devices based on InAs/GaAs QDs, such as QD laser diodes $[3,11,12]$ and QD infrared photodetectors $[13,14]$. The application of a thin GaAsSb CL has also been recently reported to improve the characteristics of intermediate band solar cells based on InAs QDs, effect that was mainly ascribed to a modification of the strain [15]. The application of such a CL can be beneficial thanks to its ability to modify and thereby extend the QD ground state to longer wavelengths, so that a broadened absorption spectrum is attainable in a QD solar cell $[15,16]$. Moreover, the CL could assist the escape of holes through a two-step mechanism [7], facilitating carrier extraction from the nanostructures. Indeed, the introduction of an additional 
energy level between the QD ground state and the GaAs barrier would serve as a middle step for holes. This would reduce the hole escape time, exponential-dependent with the barrier energy, significantly increasing the extraction probability. In addition, the use of higher amounts of $\mathrm{Sb}$ in the $\mathrm{CL}$ should lead to an extended absorption edge while switching to a type-II band alignment. This kind of structures has already been proposed for solar cell applications and are predicted to provide additional benefits [17-20]. Indeed, type-II nanostructures have already been used leading to improved short-circuit current densities $\left(\mathrm{J}_{\mathrm{sc}}\right)[21,22]$. Furthermore, sunlight concentration has been found to suppress the recombination activity in type-II QDs [23], as well as to provide a fast recovery of the open-circuit voltage $\left(\mathrm{V}_{\mathrm{oc}}\right)$ in type-II quantum rings [24], as a consequence of the higher radiative lifetimes.

The focus of this work is to analyze the impact of using thin GaAsSb CLs on the performance of InAs QD solar cells. Both type-I and type-II QD-CL band alignments are studied, and the different mechanisms involved in the operation of such devices are revealed by combining different characterization techniques. In particular, this work will highlight the relevance of the wetting layer (WL)-CL band structure on the performance of a $\mathrm{QD}$ solar cell. Due to the comparative approach of this work, optimized solar cell structures or the application of an anti-reflection coating will not be necessary.

\section{Experimental details}

The series of $\mathrm{p}-\mathbf{i}-\mathrm{n}$ junction solar cells under study consists of three samples grown by molecular beam epitaxy on $n^{+}$GaAs (001) substrates under $\mathrm{As}_{4}$ overpressure. The active region (Fig. 1) consists of ten InAs QD layers grown at $450{ }^{\circ} \mathrm{C}$ by depositing $2.8 \mathrm{ML} s$ at $\sim 0.04 \mathrm{ML} \mathrm{s}^{-1}$. The QD layers were covered by a $20 \mathrm{ML}-$ thick $\mathrm{GaAs}_{1-\mathrm{x}} \mathrm{Sb}_{\mathrm{x}} \mathrm{CL}$ with nominal values of $0 \%, 10 \%$, and $20 \%$ (samples $\mathrm{Sb}_{0}, \mathrm{Sb}_{\mathrm{I}}$, and $\mathrm{Sb}_{\mathrm{II}}$, respectively). The $\mathrm{CL}$ growth temperature, known to be a critical factor affecting the final QD-GaAsSb CL configuration, was set to $470^{\circ} \mathrm{C}$ in order to avoid material migration from the $\mathrm{CL}$ at the QD top region [4]. Immediately after the $\mathrm{CL}$, a 10 ML-thick GaAs layer was grown at the same temperature (LT GaAs in Fig. 1), afterwards increased to $580^{\circ} \mathrm{C}$ for the $35 \mathrm{~nm}$-thick GaAs spacer growth, in order to avoid the formation of extended defects $[25,26]$. The whole active region was sandwiched in the middle of a $400 \mathrm{~nm}$-thick intrinsic GaAs layer, grown on a $500 \mathrm{~nm}-$ thick $n-G a A s$ base buffer and ended in a 350/150 nm-thick p-/p ${ }^{+}$GaAs layer.

The structural properties were analyzed through conventional transmission electron microscopy (TEM) techniques, using a JEOL JEM-2100 LaB6 microscope with an electron dispersive X-ray (EDX) spectrometer Oxford INCA Energy 2000 system working at $200 \mathrm{kV}$, and high resolution X-ray diffraction (XRD) analyses, performed in a Panalytical $X^{\prime}$ Pert Pro system with $\mathrm{Cu}-\mathrm{K} \alpha 1$ radiation $(1.54056 \AA)$ ). $200 \mu$ m-diameter cylindrical mesa-etched devices were processed through standard fabrication techniques using $\mathrm{AuGe} / \mathrm{Au}$ and $\mathrm{Au} / \mathrm{AuZn} / \mathrm{Au}$ for the n- and p-type contacts, respectively. The use of such small mesa diameters allows the processing of a large number of devices from the same wafer area in which the temperature gradient during growth is negligible, leading to statistically reliable results which could not be otherwise possible. Photocurrent density-voltage $(\mathrm{J}-\mathrm{V})$ measurements were conducted using a Keithley 2400 source meter. The light source is a solar simulator equipped with a $150 \mathrm{~W}$ Xenon Lamp and an AM 1.5D filter combination (Newport). The total light intensity was calibrated to $900 \mathrm{~W} / \mathrm{m}^{2}$ using a GaAs reference cell. Photocurrent (PC) spectroscopy was carried out using a Keithley 230 voltage source and a Keithley 617 electrometer, using light from a quartz halogen lamp dispersed through a $0.34 \mathrm{~m}$ -

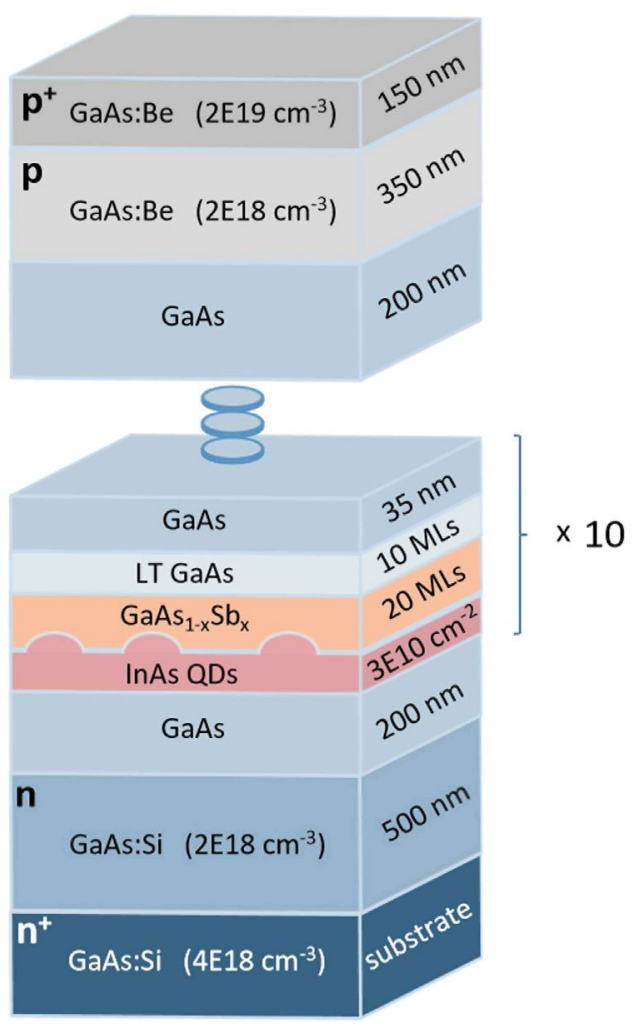

Fig. 1. Sketch of the p-i-n devices containing ten stacked InAs QD layers capped with a thin $\mathrm{GaAs}_{1-\mathrm{x}} \mathrm{Sb} \mathrm{b}_{\mathrm{x}} \mathrm{CL}$. The QD density per layer is $3 \cdot 10^{10} \mathrm{~cm}^{-2}$.

monochromator. Electroluminescence (EL) spectroscopy was also performed, detecting the emitted light with a liquid nitrogencooled $\mathrm{Ge}$ detector after dispersion through a $1 \mathrm{~m}$-spectrometer. Finally, a commercial laser diode at $781 \mathrm{~nm}$ was used to analyze the effect of light power density on the Voc. Some experimental results from the same $\mathrm{Sb}_{0}$ and $\mathrm{Sb}_{\mathrm{I}}$ devices can be found elsewhere [16]. In this work additional experimental and theoretical analyses were carried out to complete the understanding of the impact of the band alignment on the device performance.

\section{Results and discussions}

\subsection{Compositional and structural analysis}

The $\mathrm{Sb}$ content in the CL was first estimated in cross sectional TEM samples by $1 \mathrm{~nm}$ probe EDX. The amounts for samples $\mathrm{Sb}_{\mathrm{I}}$ and $\mathrm{Sb}_{\text {II }}$ were found to be approximately $10 \%$ and $24 \%$, respectively, in agreement with the nominal values. Fig. 2(a), (b), and (c) show dark-field 002 cross-sectional TEM images of representative global views from the ten stacked $\mathrm{QD}$ layers in samples $\mathrm{Sb}_{0}, \mathrm{Sb}_{\mathrm{I}}$, and $\mathrm{Sb}_{\mathrm{II}}$, respectively. Through this chemically sensitive imaging mode, the Sb-containing layers are distinguished by a brighter contrast so that averaged CL thicknesses of approximately $5.5 \mathrm{~nm}$ were estimated in both $\mathrm{Sb}$-containing samples. While samples $\mathrm{Sb}_{0}$ and $\mathrm{Sb}_{\mathrm{I}}$ present flat growth fronts all through the stacked layers (Fig. 2(a) and (b)), the growth front in sample $\mathrm{Sb}_{\text {II }}$ progressively bends, as the number of stacked layers increases (Fig. 2(c)). In this case, the high Sb content is leading to a highly strained structure, resulting in the origination of extended defects. This difference can be clearly observed in the bright-field images (Fig. 2(d), (e), and (f)), taken along the 220 g-vector direction. Besides the typical contrast associated to the QDs, the presence of threading dislocations, generated at the bottom layer and crossing upwards through the whole structure, is 

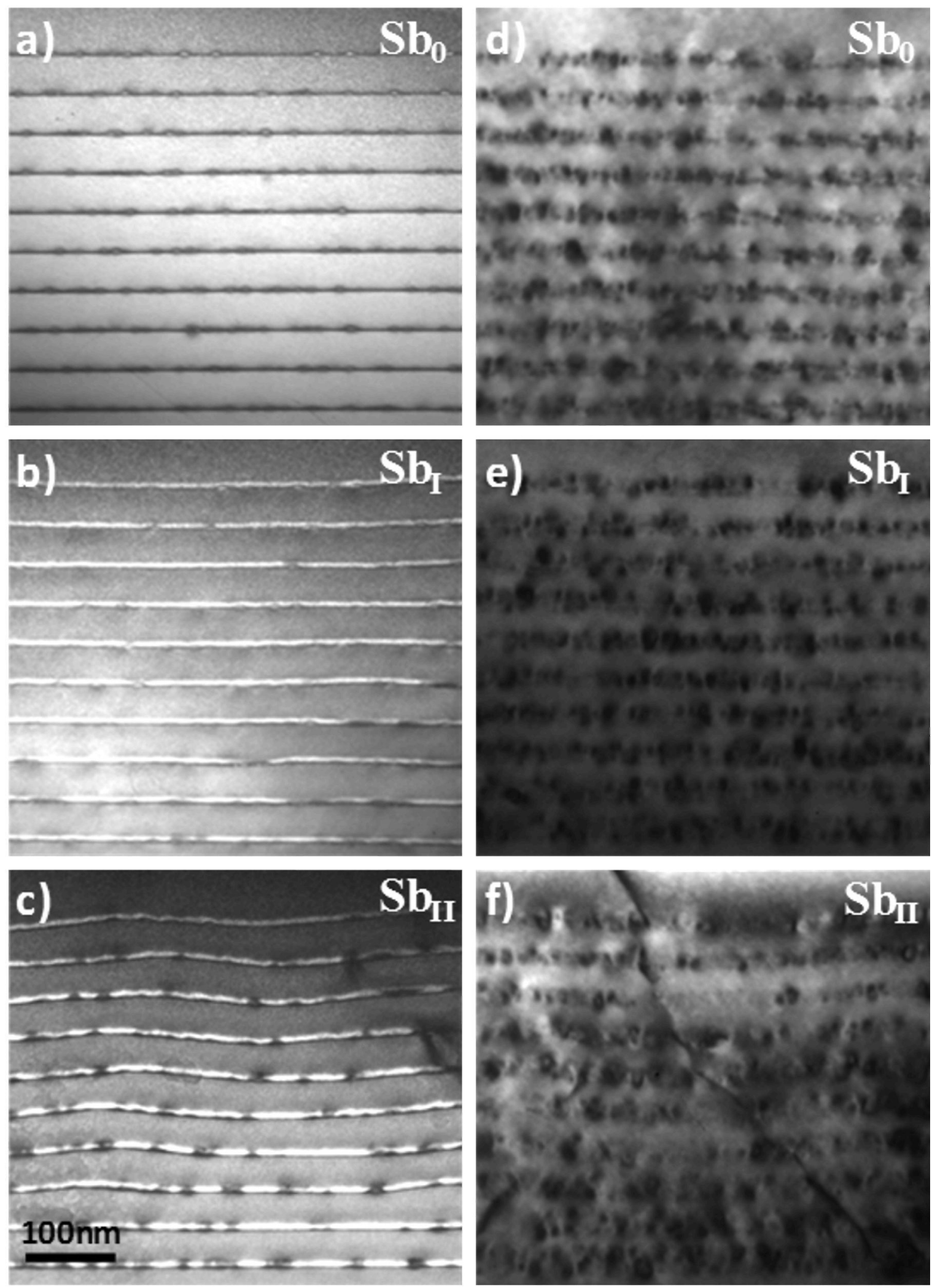

Fig. 2. Dark-field cross-sectional TEM images at the [110] pole using the 002 diffraction condition displaying representative global views of the ten stacked QD layers in samples $\mathrm{Sb}_{0}(\mathrm{a}), \mathrm{Sb}_{\mathrm{I}}(\mathrm{b})$ and $\mathrm{Sb}_{\mathrm{II}}$ (c). A brighter contrast differentiates GaAsSb CLs from the darker WL-QD one. Bright-field images using the 220 diffraction condition from similar regions in $S_{b}(d), S b_{I}(e)$ and $S b_{I I}(f)$, reveal the presence of extended defects in $S_{\mathrm{II}}$. Scale bar, corresponding to $100 \mathrm{~nm}$, is valid for figure (a-f).

revealed in $\mathrm{Sb}_{\mathrm{II}}$. Since the QDs are not strain-coupled, they are not vertically aligned in our structures, so that the effect of $\mathrm{Sb}$ on the alignment homogeneity suggested by W.-S. Liu et al. [15] will not be involved in the device performance in our case.
Fig. 3 shows high resolution XRD $\theta-2 \theta$ scans around the 004 reflection for samples $\mathrm{Sb}_{0}, \mathrm{Sb}_{\mathrm{I}}$, and $\mathrm{Sb}_{\mathrm{II}}$. The accumulation of compressive strain due to the introduction of QDs and the increase in the $\mathrm{Sb}$ content is directly reflected by the shift of the 


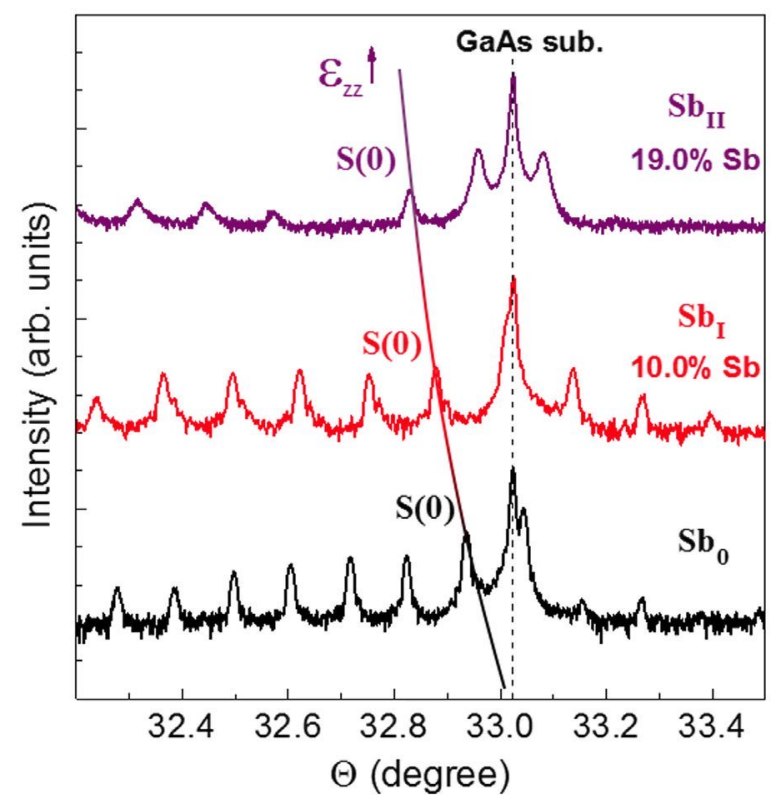

Fig. 3. $\theta / 2 \theta \mathrm{XRD}$ scans around 004 Bragg reflection performed on all the samples revealing an increasing accumulation of strain with increasing Sb content.

superlattice mean peak $(S(0))$ to a lower angle with respect to the GaAs Bragg angle. The XRD measurements, which yield average information over an extended sample area $\left(\sim 1 \mathrm{~mm}^{2}\right)$, allow estimating an average superlattice period, found to be $40 \mathrm{~nm}$ in $\mathrm{Sb}_{\mathrm{I}}$, $43 \mathrm{~nm}$ in $\mathrm{Sb}_{\text {II }}$, and $48 \mathrm{~nm}$ in $\mathrm{Sb}_{0}$, in a good agreement with values found from local TEM measurements: 40,44 , and $50 \mathrm{~nm}$, respectively. The significantly longer period for $\mathrm{Sb}_{0}$ is a consequence of a deviation from the nominal growth rate $\left(1 \mathrm{ML} \mathrm{s}^{-1}\right)$. X'Pert Epitaxy software was used to make additional estimates for the Sb content in the CLs from the measured XRD spectra. Using a superlattice period thickness of $40 \mathrm{~nm}\left(\mathrm{Sb}_{\mathrm{I}}\right)$ and $43\left(\mathrm{Sb}_{\mathrm{II}}\right)$, as determined by $X R D$, and the CL thickness of $5.5 \mathrm{~nm}$ found by TEM, it is only necessary defining a thickness for the WL in order to determine the $\mathrm{Sb}$ content in the CL. Assuming therefore a WL thickness of $0.5 \mathrm{~nm}$ [7] leads to $\mathrm{Sb}$ content estimates of $10.0 \%$ and $19.0 \%$ in $\mathrm{Sb}_{\mathrm{I}}$ and $\mathrm{Sb}_{\mathrm{II}}$, respectively. The estimation for $\mathrm{Sb}_{\mathrm{I}}(10.0 \%)$ is in perfect agreement with the value found by $\operatorname{EDX}(10 \%)$. In the case of $\mathrm{Sb}_{\mathrm{II}}$, a somewhat lower amount of Sb is drawn from the XRD simulation (19\% vs. 24\% EDX estimation). As we have shown in our previous paper where EDX Sb profiles were carried out [27], the GaAsSb CL is not homogeneous, with an accumulation of $\mathrm{Sb}$ in the upper interface and a depletion just above the WL. Our punctual EDX measurements were made just in the Sb-rich region and this could explain the higher values compared to the XRD results in $\mathrm{Sb}_{\mathrm{II}}$.

\subsection{Structure simulation}

In order to model our structures, we have simulated the electronic structure of two independent systems, which will help us in the development of the forthcoming discussion. The first system comprises a single QD on top of a WL and covered by a GaAsSb CL (QD-CL). The stacking effect is introduced in the calculation by imposing periodic boundary conditions along the growth axis. The second system is a superlattice which contains three layers, namely the WL, the GaAsSb CL and the GaAs spacer (WL-CL). We have proceeded in this way to identify the electronic structure of the WL in the inter-dot region. The direct procedure of extending the simulation region to describe simultaneously the QD and the inter-dot region would have required computational resources far from our current capabilities.
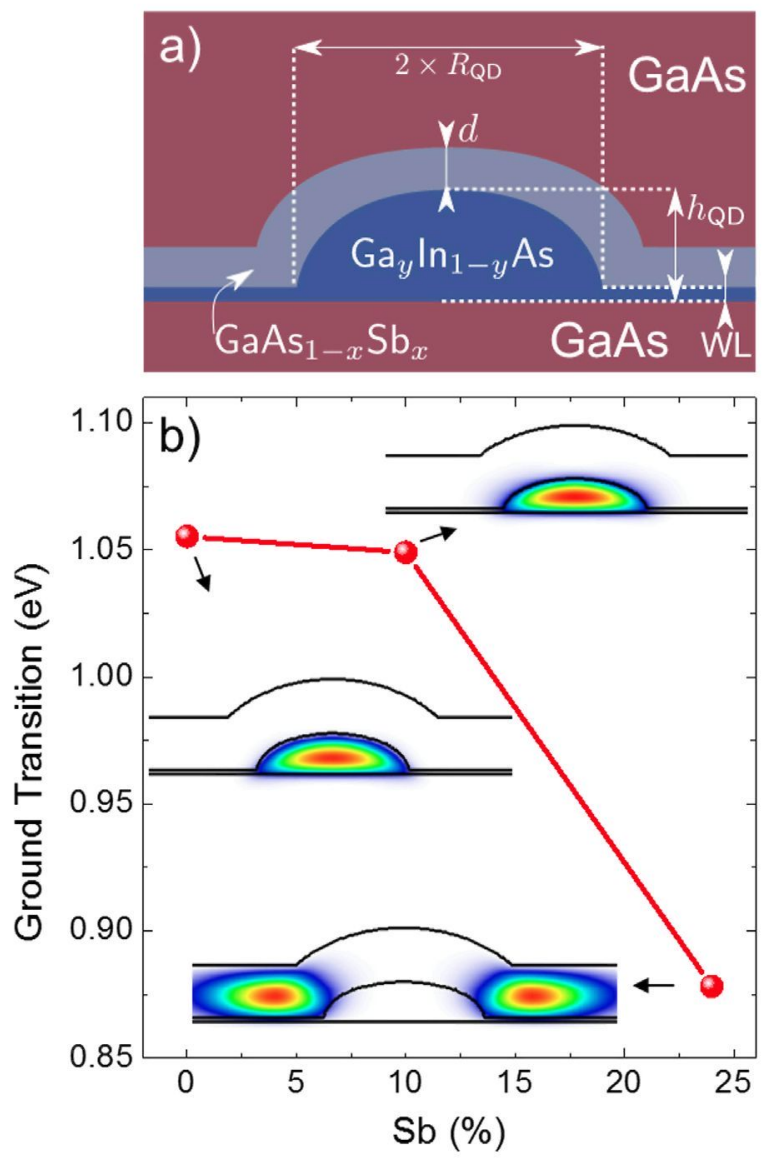

Fig. 4. (a) Geometrical parameters introduced in the calculation to describe the QD, cladding and capping regions. (b) Energy estimated for the fundamental transition of the QDs for different Sb contents in the CL together with a cross-section in the plane (110) of the hole ground state probability density.

The QD has been theoretically modeled considering the structural data obtained by TEM and XRD. A scheme depicting the most relevant geometrical parameters in our description of the nanostructure is shown in Fig. 4(a). The Nextnano ++ package [28] was used to solve the eight multiband Schrödinger equation and determine the electronic structure. All material parameters were extracted from Ref. [29]. Self-assembled QDs are the result of a lattice strain relaxation process. The effect of this strain is included in our model to obtain a realistic electronic structure description. In addition, the strain also induces the appearance of piezoelectric charges which results in the formation of an electrostatic potential. We have introduced the effect of this potential, by solving the Poisson's equation. The QD-CL electronic structure has been used to verify the expected band alignments in $\mathrm{Sb}_{\mathrm{I}}$ and $\mathrm{Sb}_{\mathrm{II}}$. The $\mathrm{QD}$ is represented by a hemi-ellipsoid volume using the averaged estimations of the base radius and height. The actual geometrical values of radius $\left(\mathrm{R}_{\mathrm{QD}}\right)$ and height $\left(\mathrm{h}_{\mathrm{QD}}\right)$ depend on the $\mathrm{Sb}$ concentration, being the values of $\left\{\mathrm{R}_{\mathrm{QD}}, \mathrm{H}_{\mathrm{QD}}\right\}$ in $\mathrm{nm}$ : $\{8.5,4.7\}$ for $\mathrm{Sb}_{0}$, $\{8.0,3.8\}$ for $\mathrm{Sb}_{\mathrm{I}}$ and $\{9.0,4.6\}$ for $\mathrm{Sb}_{\mathrm{II}}[27]$. The WL thickness is fixed to $0.5 \mathrm{~nm}$ and the $\mathrm{CL}$ to $5.5 \mathrm{~nm}$. The Gallium content in the QD is fixed to $x=21.5 \%$ to get a good agreement between the theoretical and experimental value of the emission energy of the reference sample (without GaAsSb $\mathrm{CL}$ ). The evolution of the transition energy with the Sb content is shown in Fig. 4(b). We have also included a cross-section of the hole ground state density of probability to show how the increase of Sb in the CL is responsible for a transition from type-I to type-II band alignment. The hole is confined within the QD for zero and $10 \%$ Sb content, while for $24 \%$ the wave function is expelled out the nanostructure, 

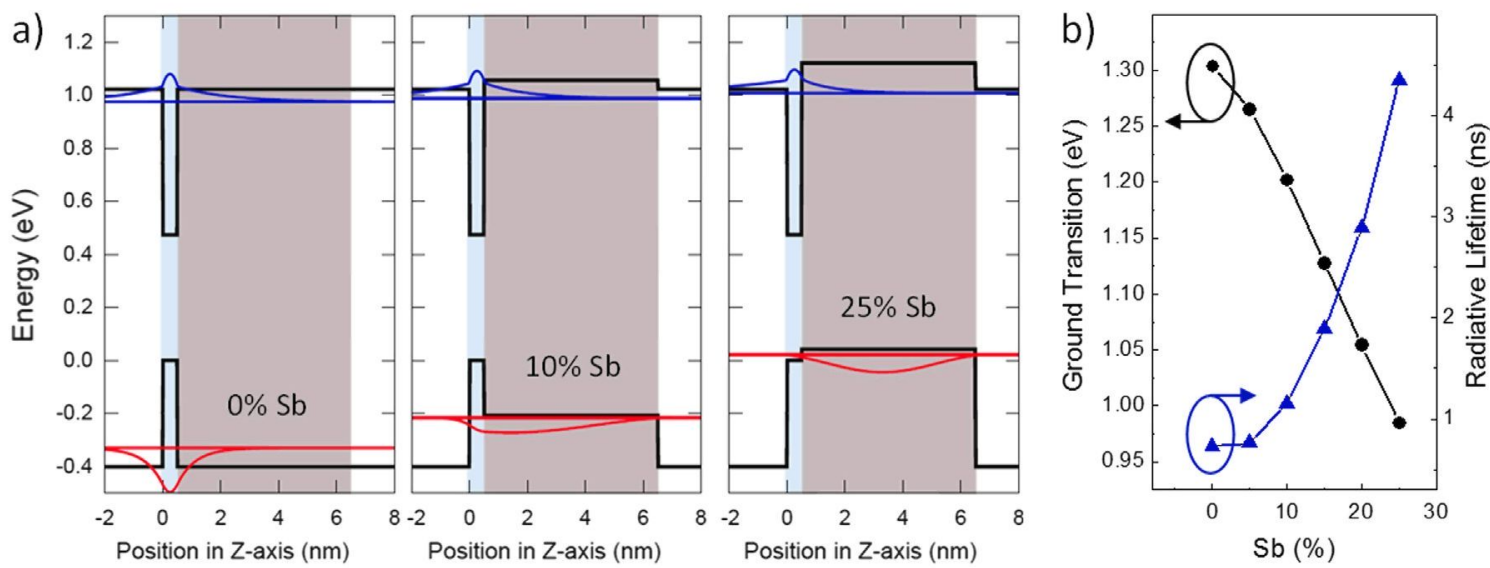

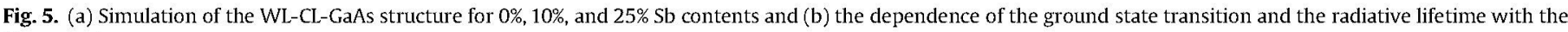
Sb content.

being localized in the CL [7]. Such a change in the type of band alignment has a great impact on the recombination rate. Indeed, the compute radiative lifetime is 0.50 and $0.52 \mathrm{~ns}$ for $\mathrm{Sb}_{0}$ and $\mathrm{Sb}_{\mathrm{I}}$, respectively, and a significantly larger one for $\mathrm{Sb}_{\mathrm{II}}, 60 \mathrm{~ns}$.

Similarly, the WL-CL band structures have also been simulated using the same thicknesses considered above $(0.5$ and $5.5 \mathrm{~nm}$, respectively). The evolution of the periodic (WL-CL-GaAs) band structure, with $0 \%, 10 \%$ and $25 \% \mathrm{Sb}$ contents in the CL, is depicted in Fig. 5(a), where the red and blue continuous curves represent the hole and electron wavefunction, respectively, at the ground states (horizontal lines). As observed, the structure shows a type-II band alignment in both $\mathrm{Sb}_{\mathrm{I}}$ and $\mathrm{Sb}_{\mathrm{II}}$, in which the holes are delocalized towards the GaAsSb CL. Fig. 5(b) shows the estimated WL$\mathrm{CL}$ ground state energy and radiative lifetimes as a function of the Sb content. The energy for the InAs WL transition (sample $\mathrm{Sb}_{0}$ ) is estimated to be $1304 \mathrm{meV}(951 \mathrm{~nm})$. The position of the ground state transition corresponds to an energy of $1202 \mathrm{meV}$ in case of $\mathrm{Sb}_{\mathrm{I}}$ ( $\mathrm{Sb}$ content of $10 \%$ ) and ranges between 1069 and $999 \mathrm{meV}$ for $\mathrm{Sb}_{\mathrm{II}}$, $\mathrm{Sb}$ content of $19-24 \%$, according to XRD and EDX, respectively). Radiative lifetimes were estimated at $\sim 1.1 \mathrm{~ns}$ for $\mathrm{Sb}_{\mathrm{I}}$, and ranging between 2.7 and $4.0 \mathrm{~ns}$ for $\mathrm{Sb}_{\mathrm{II}}$, significantly increasing with respect to that in a simple InAs WL $(0.7 \mathrm{~ns})$. Such an increase is a consequence of the transition to a type-II band alignment; its impact on solar cell performance is commented hereafter.

\subsection{Photocurrent analysis}

Representative PC spectra from samples $\mathrm{Sb}_{0}, \mathrm{Sb}_{\mathrm{I}}$, and $\mathrm{Sb}_{\mathrm{II}}$ are represented in Fig. 6(a), (b), and (c), respectively. Relatively small dispersion was found testing a number of devices between 40 and 60 within each sample. Normalized EL measurements of the same devices under different injection current densities are also shown

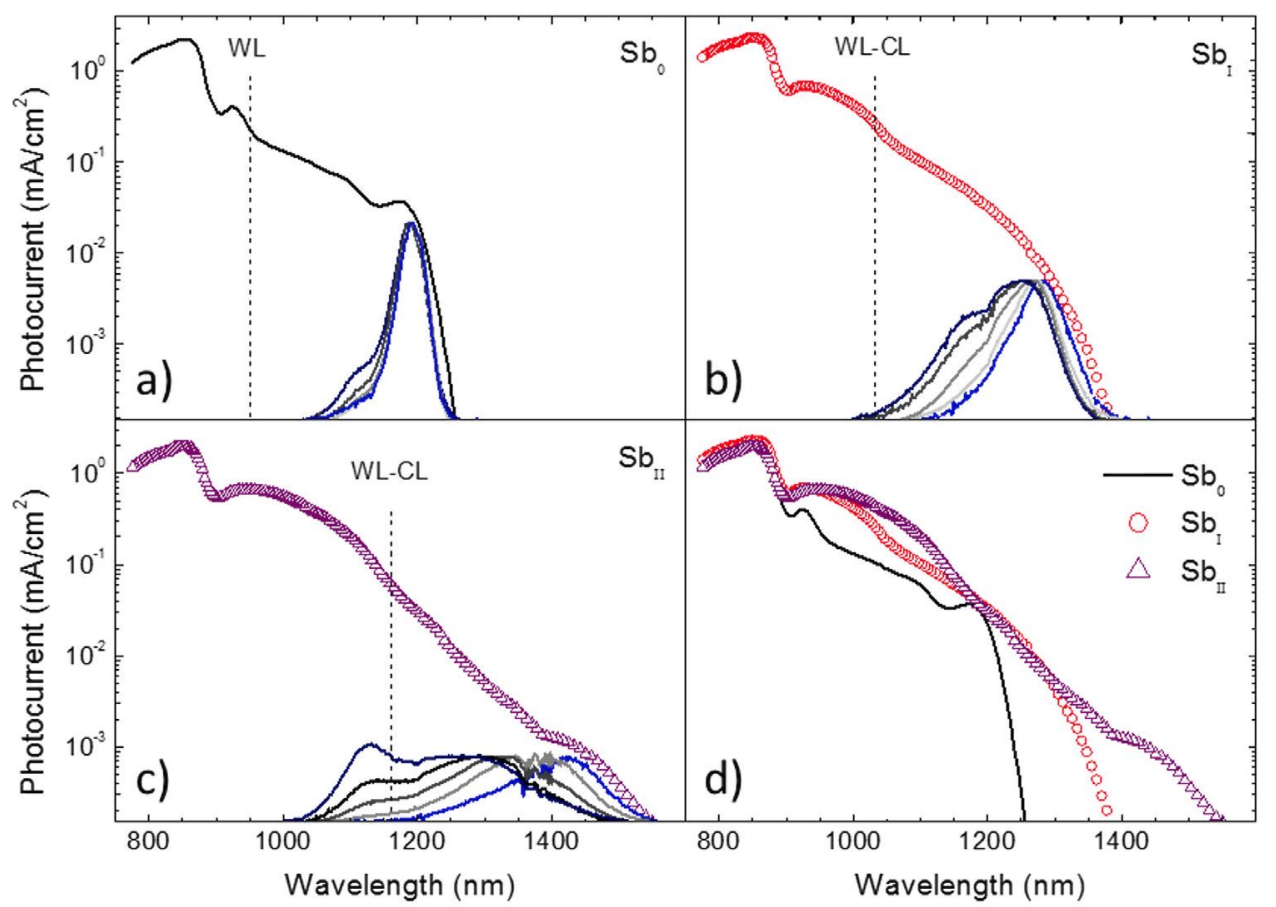

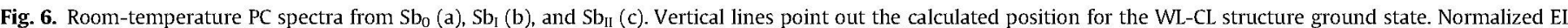

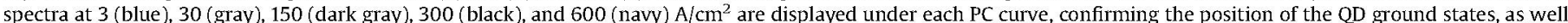

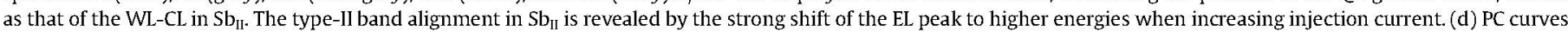

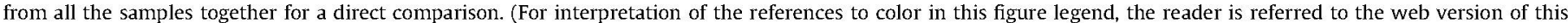
article.). 
under the PC curves in order to verify the position of the QD ground state transition as well as to confirm the type-II band alignment in $\mathrm{Sb}_{\mathrm{II}}$, which is verified by the shift of the EL peak to higher energies [30]. A significant contribution from the QDs to the $P C$ is observed in sample $\mathrm{Sb}_{0}$, both from the ground and first excited states. The WL is also providing a strong contribution, whose position matches quite well with the value previously estimated from simulations and is indicated with a vertical line. On the other hand, the presence of the $\mathrm{CL}$ in $\mathrm{Sb}_{\mathrm{I}}$ extends the absorption edge to longer wavelengths through the tuning of the QD ground state. Moreover, the CL itself is also giving rise to a strong contribution to the PC spectrum. In fact, a clear shoulder is observed at the wavelength estimated for the WL-CL ground state. The higher Sb content in the CL extends even further the photoresponse in $\mathrm{Sb}_{\mathrm{II}}$. In this case, the EL peak under low injection current densities defines the QD ground state and matches with the absorption edge observed in PC at long wavelengths, so that it can be ascribed to the absorption from the type-II QDs. The QD ground state energy is not properly reproduced by the model in $\mathrm{Sb}_{\mathrm{I}}$ (further work is needed in this case), but it is accurately predicted in $\mathrm{Sb}_{\mathrm{II}}$. For higher injection current densities, the ground state shifts to higher energies, owing to the carrier-induced band bending, typical for type-II structures [30]. Moreover, a new emission peak arises at around $1130 \mathrm{~nm}(1097 \mathrm{meV})$ at high currents. This peak is located close to the ground state transition estimated for the WL-CL according to the average Sb content estimated by XRD (19\%) and gives rise to the absorption shoulder observed in PC at the same wavelengths. The PC spectra from all the samples are shown together in Fig. 6(d) for a clear comparison of the PC evolution as the Sb content increases. A clear enhancement of the PC in the long wavelength region is observed with the $\mathrm{Sb}$ content, being extended beyond $1.5 \mu \mathrm{m}$ in $\mathrm{Sb}_{\mathrm{II}}$.

The introduction of quantum wells in the host material has been found to affect the transport of carriers drifting through the structure. This has been clearly observed, for instance, in N-containing structures, where the electron trapping is intensified by the strong impact of $\mathrm{N}$ in the conduction band [16,31]. Only a slight reduction of the collected carriers photogenerated in GaAs would be sufficient to significantly reduce the overall $P C$, so that the possible negative impact of the CL might be critical for the final solar cell performance [31]. Indeed, I-V measurements (not shown) revealed that a complete carrier collection, reflected in a saturation of the photogenerated current [32], is only achieved in all the samples under reverse bias conditions. Biasing had no impact on an equivalent sample with no QDs, in which a complete carrier collection is already achieved under photovoltaic conditions $(0 \mathrm{~V})$, so that any enhancement of the collected photogenerated current must be due to other factors rather than to a possible enlargement of the depletion region. In order to evaluate the impact on carrier transport and the contribution from the nanostructures to the $\mathrm{PC}$, the integrated $\mathrm{PC}$ at both $0 \mathrm{~V}$ and $-3 \mathrm{~V}$ has been evaluated (at $-3 \mathrm{~V}$ all the samples show complete carrier collection). Table 1 shows the integrated PC calculated in two distinguished regions. $\mathrm{PC}_{\mathrm{GaAs}}$ designates the integrated $\mathrm{PC}$ between 1.37 and $1.6 \mathrm{eV}(775-905 \mathrm{~nm})$, roughly corresponding to the GaAs contribution to the $\mathrm{PC}$ in the measured range of wavelengths, while $\mathrm{PC}_{\mathrm{QD}-\mathrm{CL}}$ designates the integrated $\mathrm{PC}$ for energies below $1.37 \mathrm{eV}$, quantifying the contribution of the QD-CL structures. For a simpler comparison, both values have been normalized to that of $\mathrm{PC}_{\mathrm{GaAs}}$ in sample $\mathrm{Sb}_{\mathrm{I}}$, the highest measured value under $0 \mathrm{~V}$ conditions. The relative increase $\triangle \mathrm{PC}=[\mathrm{PC}(-3 \mathrm{~V})-\mathrm{PC}(0 \mathrm{~V})] / \mathrm{PC}(0 \mathrm{~V})$, is also shown in Table 1 for both ranges of wavelengths. The main conclusions drawn from the values in Table 1 are the following:

- The comparison at $0 \mathrm{~V}$ reveals that the presence of InAs QDs is hindering the collection of carriers photogenerated at GaAs.
Table 1

Estimation of the integrated $P C$ between 1.37 and $1.6 \mathrm{eV}\left(\mathrm{PC}_{\mathrm{GaAs}}\right)$, related to the GaAs absorption, and for energies under $1.37 \mathrm{eV}\left(\mathrm{PC}_{\mathrm{QD}-\mathrm{CL}}\right)$, corresponding to the contribution from the nanostructures (QD-CL). The estimations under 0 and $-3 \mathrm{~V}$ are shown, roughly corresponding to electric fields in the intrinsic region of $17.5 \mathrm{kV} / \mathrm{cm}$ and $55 \mathrm{kV} / \mathrm{cm}$, respectively. For a simpler comparison, all the values have been normalized to that of $\mathrm{PC}_{\mathrm{GaAs}}$ in sample $\mathrm{Sb}_{\mathrm{I}}$, the highest measured value under $0 \mathrm{~V}$ conditions. $\triangle \mathrm{PC}$ represents the relative increase for both ranges of wavelengths, which is defined as $\triangle \mathrm{PC}=100 \cdot[\mathrm{PC}(-3 \mathrm{~V})-\mathrm{PC}(0 \mathrm{~V})] / \mathrm{PC}(0 \mathrm{~V})$

\begin{tabular}{|c|c|c|c|c|c|c|}
\hline & \multicolumn{3}{|c|}{$\mathrm{PC}_{\mathrm{GaAs}}$} & \multicolumn{3}{|c|}{$\mathrm{PC}_{\mathrm{QD}-\mathrm{CL}}$} \\
\hline & $0 \mathrm{~V}$ & $-3 V$ & $\Delta \mathrm{PC}_{\mathrm{GaAs}}(\%)$ & $0 \mathrm{~V}$ & $-3 \mathrm{~V}$ & $\Delta \mathrm{PC}_{\mathrm{QD}-\mathrm{CL}}(\%)$ \\
\hline $\mathrm{Sb}_{0}$ & 0.94 & 1.14 & 21 & 0.13 & 0.21 & 62 \\
\hline $\mathrm{Sb}_{1}$ & 1 & 1.13 & 13 & 0.31 & 0.38 & 23 \\
\hline $\mathrm{Sb}_{\mathrm{II}}$ & 0.84 & 1.10 & 31 & 0.47 & 0.62 & 32 \\
\hline
\end{tabular}

Nevertheless, this effect is partially inhibited by the introduction of the GaAsSb CL. This is evidenced by the improved $\mathrm{PC}_{\mathrm{GaAs}}$ in $\mathrm{Sb}_{\mathrm{I}}$ as compared to $\mathrm{Sb}_{0}$ under photovoltaic conditions. This suggests that the sole presence of a thin WL might be affecting the transport of carriers through the structure, as it has already been proposed in other devices [14], and that the type-II band alignment exhibited by the WL-CL structure leads to a more efficient carrier collection at $0 \mathrm{~V}$. Indeed, since the relative section occupied by the QDs is only a fraction around $10 \%$ of the overall device section [7], the trapping of carriers drifting through the structure must occur most likely at the WL. As shown in Section 3.2, the type-II band alignment increases carrier radiative lifetime in the WL compared to the reference sample $\mathrm{Sb}_{0}$, which would reduce radiative recombination of trapped carriers and facilitate thermal carrier escape and electric field collection. Since carriers photogenerated at GaAs have the highest relative weight in the overall $\mathrm{PC}$, avoiding losses of carriers trapped at the WL has a significant impact on the device performance.

- The analysis at reverse bias shows a much smaller relative increase of $\mathrm{PC}_{\mathrm{QD}-\mathrm{CL}}$ from $0 \mathrm{~V}$ to $-3 \mathrm{~V}$ in both $\mathrm{Sb}_{\mathrm{I}}$ and $\mathrm{Sb}_{\mathrm{II}}$ than that in $\mathrm{Sb}_{0}(23 \%$ and $32 \%$ vs. $62 \%$, respectively). This indicates an improved carrier extraction from the nanostructures with the addition of the GaAsSb CL. This could be likely related to a twostep hole escape mechanism in the type-I structure (from the $\mathrm{QD}$ to the GaAsSb CL and from the CL to the GaAs barrier) and to the longer hole lifetimes in the type-II sample.

- The use of a high Sb content induces a lower $\mathrm{PC}_{\mathrm{GaAs}}$ in $\mathrm{Sb}_{\mathrm{II}}$ at $0 \mathrm{~V}$ as compared to the other samples. This is expected both from the presence of extended defects and the introduction of deep hole levels in the structure. Remarkably, the relative increases in $\mathrm{PC}_{\mathrm{QD}-\mathrm{CL}}$ and $\mathrm{PC}_{\mathrm{GaAs}}$ in $\mathrm{Sb}_{\mathrm{II}}$ are approximately the same (32\% vs. $31 \%$, respectively). This suggests that, in this sample, a mechanism other than carrier trapping or a hindered extraction from the nanostructures is involved in the incomplete carrier collection under photovoltaic conditions, affecting in a similar extent carriers photogenerated in any region of the device. It is known that, in the presence of defects, the collection efficiency strongly depends on the thickness of the intrinsic region and the drift lengths of carriers which, in turn, directly depend on the carrier lifetime and the built-in field [33]. In the case of $\mathrm{Sb}_{\mathrm{II}}$ it can be assumed that defect-induced non-radiative recombination is reduced by stronger built-in fields, increasing drift lengths and allowing a more efficient carrier collection by the application of reverse bias [34].

- Despite the presence of extended defects, $\mathrm{Sb}_{\mathrm{II}}$ shows the highest contribution from the nanostructures. Indeed, $\mathrm{PC}_{\mathrm{QD}-\mathrm{CL}}$ at $0 \mathrm{~V}$ increases with the $\mathrm{Sb}$ content. This enhancement is due to the extension of the absorption edge to longer wavelengths, the strong contribution of the $\mathrm{CL}$, and the type-II WL-CL structure. 
In addition, despite the lower $\mathrm{PC}_{\mathrm{GaAs}}$ due to the presence of defects, the overall integrated $P C$ under photovoltaic conditions in $\mathrm{Sb}_{\mathrm{II}}$, i.e., the addition of $\mathrm{PC}_{\mathrm{GaAs}}$ and $\mathrm{PC} \mathrm{CD}_{\mathrm{CL}}$, is as high as that in $\mathrm{Sb}_{\mathrm{I}}$, strongly exceeding it at $-3 \mathrm{~V}$. Hence further benefits are expected from such structures if the creation of dislocations is inhibited, what would allow improved carrier collection efficiencies for higher $\mathrm{Sb}$ contents, providing a higher $\mathrm{J}_{\mathrm{sc}}$. This is feasible, for instance, through strain-balancing techniques, such as the use of $\mathrm{N}$ - or P-containing strain-compensating spacer layers [35-37].

\subsection{Solar cell performance}

J-V curves of the set of samples under AM1.5D spectrum are depicted in Fig. 7(a). The use of the GaAsSb $\mathrm{CL}$ in sample $\mathrm{Sb}_{\mathrm{I}}$ induces a small reduction of $0.033 \mathrm{~V}$ in $\mathrm{V}_{\mathrm{oc}}$ with respect to $\mathrm{Sb}_{0}$ $\left(V_{o c}=0.585 \mathrm{~V}\right)$. Nevertheless, $J_{s c}$ is increased by almost $15 \%$. An enhancement of $\mathrm{J}_{s c}$ has already been reported by using GaAsSb CLs with $10 \% \mathrm{Sb}$ in strain-coupled structures [15]. Indeed, the $\mathrm{J}_{\mathrm{sc}}$ values reported by W.-S. Liu et al. [15] were significantly higher than ours, likely partially due to the use of an optimized solar cell structure. Nevertheless, higher $\mathrm{Sb}$ contents leading to a type-II structure resulted in that work in a reduced $\mathrm{J}_{\mathrm{sc}}$ [15]. In our case, although $\mathrm{V}_{\mathrm{oc}}$ in $\mathrm{Sb}_{\mathrm{II}}$ is further decreased in $0.059 \mathrm{~V}, \mathrm{~J}_{\mathrm{Sc}}$ remains virtually unaltered as compared with $\mathrm{Sb}_{\mathrm{I}}$. Hence, $\mathrm{Sb}_{\mathrm{I}}$ and $\mathrm{Sb}_{\mathrm{II}}$ exceed the external quantum efficiency of $\mathrm{Sb}_{0}$ by $20 \%$ and a $10 \%$, respectively, despite the significant introduction of additional accumulated strain and, in case of $\mathrm{Sb}_{\mathrm{II}}$, extended defects [38]. The extended PC, the contribution from the $\mathrm{CL}$ and the improved carrier collection discussed previously are likely behind the conversion efficiency enhancement.

Finally, the impact of light concentration on $V_{o c}$ has been analyzed in the set of samples. For this purpose, a commercial laser diode at $781 \mathrm{~nm}$ was employed, whose incident power was calibrated by the use of an attenuating filter. Fig. 7(b) shows the evolution of the monochromatic $V_{o c}$ as a function of the light power. Dashed lines represent the expected $V_{o c}$ according to the ideality factors deduced from the dark I-V curves: $1.40\left(\mathrm{Sb}_{0}\right), 1.36$ $\left(\mathrm{Sb}_{\mathrm{I}}\right)$, and $1.36\left(\mathrm{Sb}_{\mathrm{II}}\right)$. The $\mathrm{V}_{\mathrm{oc}}$ of $\mathrm{Sb}_{\mathrm{O}}$ follows the expected evolution, consistently with the diode equation. Remarkably, $\mathrm{V}_{\mathrm{oc}}$ in $\mathrm{Sb}_{\mathrm{II}}$ follows an increasing tendency with light power faster than expected from the dark I-V curve. Indeed, the $\mathrm{V}_{\mathrm{oc}}$ of $\mathrm{Sb}_{\mathrm{II}}$ exceeds that of $\mathrm{Sb}_{0}$ under high light power ( $0.94 \mathrm{vs} .0 .92 \mathrm{~V}$ ). This fact means that light concentration is avoiding the impact of introducing a lower effective bandgap within the host material in these structures: the $\mathrm{V}_{\mathrm{oc}}$ is not limited by the low bandgap of the CLs, contrary to what happens in the case of using thicker GaAsN barriers [39]. Although a faster $V_{O C}$ increase at low concentrations would be expected in $\mathrm{Sb}_{\mathrm{II}}$ due to the Stark effect, this would never lead to an $\mathrm{V}_{\text {oc }}$ higher than that in a type-I structure. Indeed, the current generated using the highest light power is close below $30 \mathrm{~A} / \mathrm{cm}^{2}$, which was used for one of the EL measurements (gray curve in Fig. 6(c)). As can be observed in Fig. 6(c), the EL peak at such injection currents is clearly located below the energy corresponding to the $V_{o c}(0.90 \mathrm{eV}$ and $0.94 \mathrm{~V}$, respectively). This means that in $\mathrm{Sb}_{\mathrm{II}}$ high light concentrations lead to an $V_{o c}$ higher than the effective bandgap (defined by the QD ground state). This must be induced by a faster quasi-Fermi-level splitting following the faster population of the QD electronic states with light power because of the much longer radiative lifetimes in the type-II QD-CL structures. Indeed, EL emission from QD excited states and even from the WL-CL is observed in this sample at injection current levels for which emission in $\mathrm{Sb}_{0}$ and $\mathrm{Sb}_{1}$ only occurs at the $\mathrm{QD}$ ground state (Fig. 6).

Regarding $\mathrm{Sb}_{\mathrm{I}}$, the $\mathrm{V}_{\mathrm{oc}}$ follows the tendency expected from the dark I-V curve for low light power densities, switching to a faster increasing tendency under higher light concentrations and also leading to an $\mathrm{V}_{\mathrm{oc}}$ slightly higher than in $\mathrm{Sb}_{0}$. A high light power regime is also observed in $\mathrm{Sb}_{\mathrm{II}}$, starting from some lower light concentration. Although further investigation is necessary for a good understanding, this behavior is likely related to the type-II WL-CL band structure in both $\mathrm{Sb}_{\mathrm{I}}$ and $\mathrm{Sb}_{\mathrm{II}}$.

\section{Conclusions}

In conclusion, we have presented a study on the effect of using thin GaAsSb CLs for InAs QD solar cells with two different Sb contents providing QD-CL structures with type-I and type-II band alignments. The QD absorption can be extended by increasing the $\mathrm{Sb}$ content in the $\mathrm{CL}$, achieving photoresponse up to beyond $1.5 \mu \mathrm{m}$ in the type-II structure. The CL provides a strong additional contribution to the $\mathrm{PC}$, and is found to improve the carrier collection efficiency of a reference QD solar cell, likely due to the type-II WL$\mathrm{CL}$ band alignment. Indeed, the WL-CL band alignment seems to have a stronger impact on the overall solar cell performance than the QD-CL band alignment under 1 sun illumination. An efficiency improvement of up to $20 \%$ as compared to the reference QD solar cell has been obtained when using a moderate Sb content. For high $\mathrm{Sb}$ contents, despite the larger contribution from the nanostructures to the PC, the efficiency improvement is reduced to $10 \%$. The presence of dislocations due to excessive accumulated strain is probably the main reason behind this effect. Nevertheless, an especially faster $V_{o c}$ increase is found under light concentration in this case, slightly exceeding that of the reference QD solar cell in
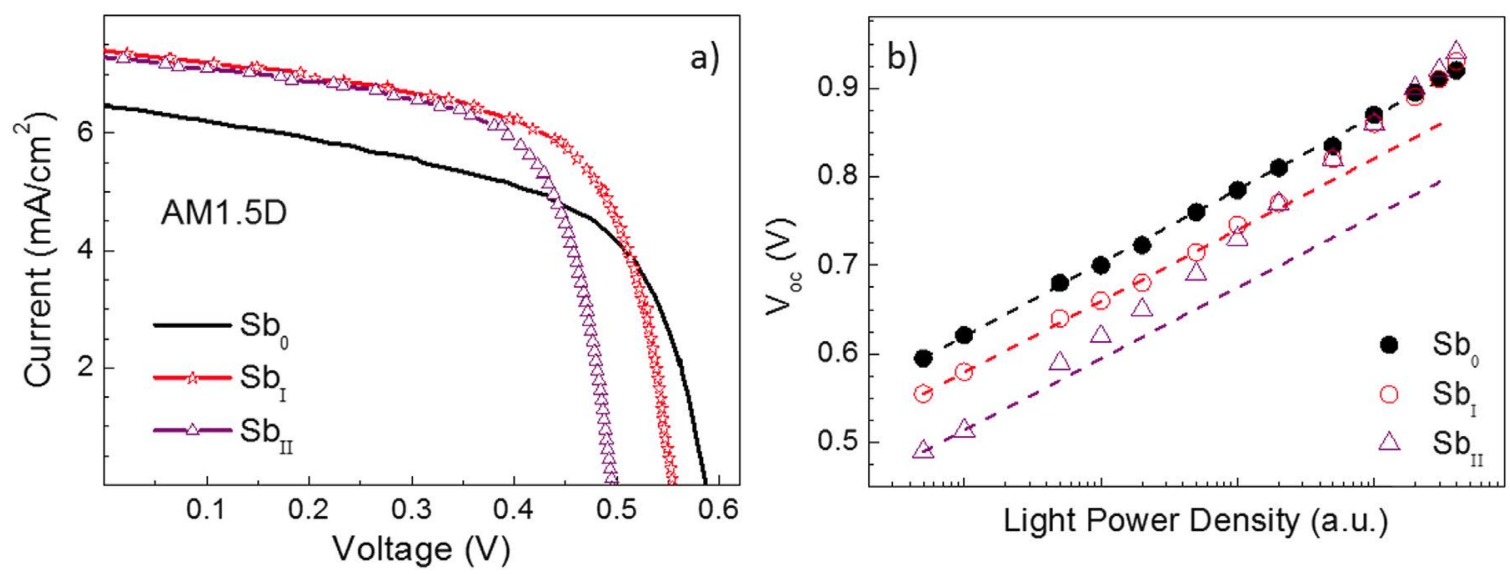

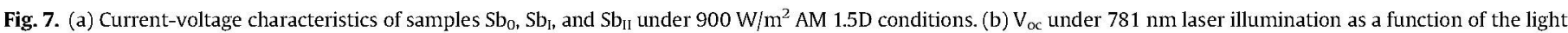
power density. 
both Sb-containing devices. The type-II band alignment in both the QD-CL and the WL-CL structures appears as a competing factor, allowing an enhanced improvement of the $\mathrm{V}_{\mathrm{oc}}$ under light concentration.

\section{Acknowledgments}

We acknowledge the Spanish MICINN-MINECO for funding through project MAT2013-47102-C2-2-R. JMLL and IA acknowledge the financial support of the Comunidad Autónoma de Madrid (Grant S2013/MAE-2780), TEC2015-64189-C3-2-R (MINECO/FEDER) and MINECO (Grant AIC-B_2011-0806). We would also like to thank Alicia Fraile (ISOM-UPM) for processing the samples.

\section{Appendix A. Supplementary material}

Supplementary data associated with this article can be found in the online version at http://dx.doi.org/10.1016/j.solmat.2016.09. 006.

\section{References}

[1] K. Akahane, N. Yamamoto, N. Ohtani, Long-wavelength light emission from InAs quantum dots covered by GaAsSb grown on GaAs substrates, Physica E 21 (2004) 295.

[2] J.M. Ripalda, D. Granados, Y González, A.M. Sánchez, S.I Molina, J.M. García Room temperature emission at $1.6 \mu \mathrm{m}$ from InGaAs quantum dots capped with GaAsSb, Appl. Phys. Lett. 87 (2005) 202108.

[3] H.Y. Liu, M.J. Steer, T.J. Badcock, D.J. Mowbray, M.S. Skolnick, P. Navaretti, K. M. Groom, M. Hopkinson, R.A. Hogg, Long-wavelength light emission and lasing from InAs/GaAs quantum dots covered by a GaAsSb strain-reducing layer, Appl. Phys. Lett. 86 (2005) 143108.

[4] J.M. Ullod, I.W.D. Drouzas, P.M. Koenrad, D.J. Mowbray, M.J. Steer, H.Y Liu M. Hopkinson, Suppression of InAs/GaAs quantum dot decomposition by the incorporation of a GaAsSb capping layer, Appl. Phys. Lett. 90 (2007) 213105.

[5] J.M. Ulloa, R. Gargallo-Caballero, M. Bozkurt, M. del Moral, A. Guzman, P. M. Koenraad, A. Hierro, GaAsSb-capped InAs quantum dots: from enlarged quantum dot height to alloy fluctuations, Phys. Rev. B 81 (2010) 165305.

[6] Y.D. Jang, T.J. Badcock, D.J. Mowbray, M.S. Skolnick, J. Park, D. Lee, H.Y. Liu, M J. Steer, M. Hopkinson, Carrier lifetimes in type-II InAs quantum dots capped with a GaAsSb strain reducing layer, Appl. Phys. Lett. 92 (2008) 251905.

[7] J.M. Ulloa, J.M. Llorens, M. del Moral, M. Bozkurt, P.M. Koenraad, A. Hierro Analysis of the modified optical properties and band structure of $\mathrm{GaAs}_{1-\mathrm{x}} \mathrm{Sb}_{\mathrm{x}}-$ capped InAs/GaAs quantum dots, J. Appl. Phys. 112 (2012) 074311.

[8] P. Klenovskŷ, V. Krapek, D. Munzar, J. Humlíček, Electronic structure of InAs quantum dots with GaAsSb strain reducing layer: localization of holes and its effect on the optical properties, Appl. Phys. Lett. 97 (2012) 203107.

[9] J.M. Ulloa, J.M. Llorens, B. Alén, D.F. Reyes, D.L. Sales, D. González, A. Hierro, High efficient luminescence in type-II GaAsSb-capped InAs quantum dots upon annealing, Appl. Phys. Lett. 101 (2012) 253112.

[10] J.M. Llorens, L. Wewior, E.R. Cardozo de Oliveira, J.M. Ulloa, A.D. Utrilla, A. Guzmán, A. Hierro, B. Alén, Type II InAs/GaAsSb quantum dots: highly tunable exciton geometry and topology, Appl. Phys. Lett. 107 (2015) 183101.

[11] K. Akahane, N. Yamamoto, S.-I. Gozu, N. Ohtani, Strong photoluminescence and laser operation of InAs quantum dots covered by a GaAsSb strain-reducin layer, Physica E 26 (2005) 395.

[12] A.D. Utrilla, J.M. Ulloa, A. Guzman, A. Hierro, Impact of the Sb content on the performance of GaAsSb-capped InAs/GaAs quantum dot lasers, Appl. Phys. Lett. 103 (2013) 111114

[13] C.-T. Huang, Y.-C. Chen, S.-C. Lee, Improved photoresponse of InAs/GaAs quantum dot infrared photodetectors by using $\mathrm{GaAs}_{1} \mathrm{Sb}_{\mathrm{x}}$ strain reducing layer, Appl. Phys. Lett. 100 (2012) 043512.

[14] A. Guzmán, K. Yamamoto, J.M. Ulloa, J.M. Llorens, A. Hierro, Role of the wetting layer in the enhanced responsivity of InAs/GaAsSb quantum dot infrared photodetectors, Appl. Phys. Lett. 107 (2015) 011101

[15] W.-S. Liu, H.-M. Wu, F--H. Tsao, T.-L. Hsu, J-I. Chyi, Improving the characteristics of intermediate-band solar cell devices using a vertically aligned InAs/ GaAsSb quantum dot structure, Sol. Energy Mater. Sol. Cells 105 (2012) 237.

[16] A.D. Utrilla, J.M. Ulloa, Ž. Gačević, D.F. Reyes, I. Artacho, T. Ben, D. González, A. Hierro, A. Guzman, Impact of alloyed capping layers on the performance of InAs quantum dot solar cells, Sol. Energy Mater. Sol. Cells 144 (2016) 128.

[17] A. Pancholi, S.P. Bremner, J. Boyle, V.G. Stoleru, C.B. Honsberg, Variability of heterostructure type with thickness of barriers and temperature in the InAs! GaAsSb quantum dot system, Sol. Energy Mater. Sol. Cells 94 (2010) 1025.

[18] A. Luque, P.G. Linares, A. Mellor, V. Andreev, A. Marti, Some advantages of intermediate band solar cells based on type II quantum dots, Appl. Phys. Lett. 103 (2013) 123901

[19] S. Hatch, J. Wu, K. Sablon, P. Lam, M. Tang, Q. Jiang, H. Liu, InAs/GaAsSb quantum dot solar cells, Opt. Express 22 (2014) A679.

[20] J. Vyskočil, P. Gladkov, O. Petřiček, A. Hospodková, J. Pangrác, Growth and properties of $A^{\text {III }} B^{V} \mathrm{QD}$ structures for intermediate band solar cells, J. Appl. Phys. 414 (2015) 172.

[21] R.B. Laghumavarapu, A. Moscho, A. Khoshakhlagh, M. El-Emawy, L.F. Lester, D. L. Huffaker, GaSb/GaAs type II quantum dot solar cells for enhanced infrared spectral response, Appl. Phys. Lett. 90 (2007) 173125.

[22] P.J. Carrington, M.C. Wagener, J.R. Botha, A.M. Sanchez, A. Krier, Enhanced infrared photo-response from GaSb/GaAs quantum ring solar cells, Appl. Phys. Lett. 101 (2012) 231101.

[23] A.M. Kechiantz, L.M. Kocharyan, H.M. Kechiyants, Band alignment and conversion efficiency in Si/Ge type-II quantum dot intermediate band solar cells, Nanotechnology 18 (2007) 405401.

[24] H. Fujita, P.J. Carrington, M.C. Wagener, J.R. Botha, A.R.J. Marshall, J. James, A. Krier, K.-H. Lee, N.J. Ekins-Daukes, Open-circuit voltage recovery in type II GaSb/GaAs quantum ring solar cells under high concentration, Prog. Photovolt. 23 (2015) 1896.

[25] N.S. Beattie, G. Zoppi, P. See, I. Farrer, M. Duchamp, D.J. Morrison, R.W. Miles, D.A. Ritchie, Analysis of InAs/GaAs quantum dot solar cells using Suns-Voc measurements, Sol. Energy Mater. Sol. Cells 130 (2014) 241.

[26] S.M. Willis, J.A.R. Dimmock, F. Tutu, H.Y. Liu, M.G. Peinado, H.E. Assender, A.A R. Watt, I.R. Sellers, Defect mediated extraction in InAs/GaAs quantum dot solar cells, Sol. Energy Mater. Sol. Cells 102 (2012) 142.

[27] D. Gonzalez, D.F. Reyes, T. Ben, A.D. Utrilla, A. Guzman, A. Hierro, J.M. Ulloa, Influence of $\mathrm{Sb} / \mathrm{N}$ contents during the capping process on the morphology of InAs/GaAs quantum dots, Sol. Energy Mater. Sol. Cells 145 (2016) 154.

[28] S. Birner, T. Zibold, T. Andlauer, T. Kubis, M. Sabathil, A. Trellakis, P. Vogl, Nextnano: general purpose 3-D simulations, IEEE Trans. Electron Devices 54 (2007) 2137

[29] I. Vurgaftman, J.R. Meyer, L.R. Ram-Mohan, Band parameters for III-V compound semiconductors and their alloys, J. Appl. Phys. 89 (2001) 5815.

[30] T.T. Chen, C.L. Cheng, Y.F. Chen, F.Y. Chang, H.H. Lin, C.-T. Wu, C.H. Chen, Unusual optical properties of type-II InAs/GaAs $\mathrm{G}_{0.7} \mathrm{Sb}_{0.3}$ quantum dots by photoluminescence studies, Phys. Rev. B 75 (2007) 033310.

[31] H.M. Khalil, N. Balkan, Carrier trapping and escape time in p-i-n GaInNAs MQW structures, Nanoscale Res. Lett. 9 (2014) 21.

[32] H. Fujii, Y. Wang, K. Watanabe, M. Sugiyama, Y. Nakano, High-aspect-ratio structures for efficient light absorption and carrier transport in InGaAs/GaAsP multiple quantum well solar cells, IEEE J. Photovolt. 3 (2013) 859.

[33] J. Hubin, A.V. Shah, Effect of the recombination function on the collection in a p-i-n solar cell, Philos. Mag. B 72 (1995) 589.

[34] S.-W. Feng, C.-M. Lai, C.-H. Chen, W.-C. Sun, L.-W. Tu, Theoretical simulations of the effects of the indium content, thickness, and defect density of the i-layer on the performance of p-i-n InGaN single homojunction solar cells, J. Appl. Phys. 108 (2010) 093118.

[35] R.B. Laghumavarapu, M. El-Emawy, N. Nuntawong, A. Moscho, L.F. Lester, D. L. Huffaker, Improved device performance of InAs/GaAs quantum dot solar cells with GaP strain compensation layers, Appl. Phys. Lett. 91 (2007) 243115.

[36] S.M. Hubbard, C.D. Cress, C.G. Bailey, R.P. Raffaelle, S.G. Bailey, D.M. Wilt, Effect of strain compensation on quantum dot enhanced GaAs solar cells, Appl. Phys. Lett. 92 (2008) 123512.

[37] R. Oshima, A. Takata, Y. Okada, Strain-compensated InAs/GaNAs quantum dots for use in high efficiency solar cells, Appl. Phys. Lett. 93 (2008) 083111.

[38] A. Martí, N. López, E. Antolín, E. Cánovas, A. Luque, C.R. Stanley, C.D. Farmer, P. Díaz, Emitter degradation in quantum dot intermediate band solar cells, Appl. Phys. Lett. 90 (2007) 233510.

[39] P.G. Linares, E. López, I. Ramiro, A. Datas, E. Antolín, Y. Shoji, T. Sogabe, Y. Okada, A. Martí, A. Luque, Voltage limitation analysis in strain-balanced InAs/GaAsN quantum dot solar cells applied to the intermediate band concept, Sol. Energy Mater. Sol. Cells 132 (2015) 178. 